\title{
Microfungal communities in soil polluted with fluoride
}

\author{
Galina A. Evdokimova*, Maria V. Korneykova
}

Laboratory of Microorganisms Ecology, Institute of the North Industrial Ecology Problems, Kola Science Centre of Russian

Academy of Sciences, Apatity, Russia; *Corresponding Author: galina@inep.ksc.ru

Received 22 May 2010; revised 23 June 2010; accepted 27 June 2010.

\begin{abstract}
There have been identified three zones according to the degree of soil pollution with fluoride in the impact area of air emissions of the Kandalaksha Aluminium Smelter (Russia): zone of maximum pollution up to $2.5 \mathrm{~km}$ from the emission source with the content of fluoride from 5000 to $1200 \mathrm{mg} / \mathrm{kg}$, zone of strong pollution up to $13 \mathrm{~km}$ from the plant with the content of fluoride between $1200-400 \mathrm{mg} / \mathrm{kg}$ and zone of moderate pollution up to $20 \mathrm{~km}$ from the source with content of fluoride between $400-200 \mathrm{mg} / \mathrm{kg}$. Emissions of the aluminium plant have reduced the number and the diversity of fungi and have caused an increase in fungal communities that are potentially pathogenic fungi. The biomass of fungi has decreased in the organic horizon of the maximum polluted soil from 5.4 to $3.6 \mathrm{mg} / \mathrm{g}$. As a whole, emissions from the aluminium plant in the Murmansk region are less toxic for the environment, than emissions of copper-nickel enterprises.
\end{abstract}

Keywords: Pollution Gradient; Fluoride; Soil Fungal Communities; Number; Diversity; Structure

\section{INTRODUCTION}

The combination of high level of industrial development and extreme nature condition in the Murmansk region of Russia affect the condition of ecosystems. Traditionally in the Kola Peninsula researchers pay the most attention to the environmental pollution by heavy metals and sulphur dioxide [1-5]. At the same time, the enterprises of nonferrous metallurgy and superphosphate factories emit into the air of Murmansk region more than 800 tons of fluoride hydrogen (HF) per year. Most part from this volume (700 tons) is from Kandalaksha Aluminium Smelter (KAS). The influence on ecosystems from companies like Kandalaksha Aluminium Smelter has been insufficiently studied. The first recognized research has shown that macro- and microelements found in air emissions from KAS are accumulated considerably in the soil, mainly in its organic horizon, as well as in plants [6,7].

The main compounds in the air emissions from KAS are fluoride and aluminium $\left(\mathrm{Al}_{2} \mathrm{O}_{3}-5000 \mathrm{t} /\right.$ year $)$. In spite of the fact, that more aluminium gets to the environment with air emissions, than fluorine, the toxicity of the latter one for biota is more considerable. Fluorine and its compounds belong to the 1st class of hazard of substances and are found in emissions basically in the form of water-soluble compounds, accessible for biota compounds (up to 90\%). Aluminium belongs to the third class of hazard and is part of, basically, a solid phase of atmospheric emissions poorly accessible to live organisms (up to 98\%) [8]. Besides, the studied Al-Fe-humus soils dominating in the Kola Peninsula, contain significant amounts of aluminium $\left(\mathrm{Al}_{2} \mathrm{O}_{3}\right.$ up to $15 \%$ on anneal soil), and we can speak about the adaptation of soil microbiota to the high content of this element.

It is known, that high concentrations of fluorine and its compounds are dangerous for living organisms, including humans being [9-13]. Higher content of fluorine-ions lead to the inhibition of some enzyme reactions, to the linking of biogenous elements ( $\mathrm{P}, \mathrm{Ca}, \mathrm{Mg}$ etc.) and the disturbance of their balance in the organism. The increased concentrations of compounds of aluminium and fluorine are the reason of diseases of respiratory organs and ossa.

Microscopic fungi are essential components of the forest ecosystem. Fungi take part in the soil-forming processes mainly by destructing organic compounds (vegetable waste, humus, xenobiotic). Fungi reduce toxicity of soils by accumulation, chelatization, and detoxication of toxic elements. They perform biogenic migration of elements in soil and also are bioindicators of pollution. Change in the structure and functions of fungal communities, which in the modern biosphere, primarily relate to the anthropogenic effects may lead to abnormalities in substance transformation in soils and the biosphere as a whole.

The goal of work is to study the number and diversity 
of soil microfungi, structural changes of fungal communities in soils under influence of polluted air emissions from an aluminium plant, herein KAS as an example.

\section{MATERIAL AND METHODS}

\subsection{Stationary Plots}

The studies are carried out at stationary plots located along the KAS air emissions gradient $\left(67^{\circ} 00^{\prime} \mathrm{N}, 32^{\circ} 00^{\prime} \mathrm{E}\right)$ at 2, 5, 10, 20 and 50 (the background plot) km northwards from the plant. All the plots $\left(100 \mathrm{~m}^{2}\right)$ were established in pine forests with dwarf shrubs (predominantly, crowberry Empetrum hermaphroditum) and green mosses in the ground cover. The soil cover of territories in which the stationary plots are located, is presented by Al-Fe-humus podzol on sandy moraine. The thickness of organic horizon is about 3-5 sm. The sampling was carried out in spring, summer, autumn periods in 2003-2007 years in three replications (162 samples). The mass of each sample made 300-400 g. In 2005 year soil samples were taken from organic horizon following the pollution gradient of $0.5,1.0,1.5,2.0,3.0,4.0,5.0,7.5,10.0,12.5$, $15.0,17.5,20.0,50.0 \mathrm{~km}$ from the emission source, three replications at each point (42 samples).

\subsection{Micological Analyses}

For the micological analysis soil samples from organic horizon were taken. Totally, 204 soil samples were analysed. All analyses are carried out the next day after sampling that means fresh samples was analysed. The total the length of fungal mycelium is determined by the method of fluorescent microscopy using polycarbone membrane filters Cyclopore Blask with pores diameter of 0.8 microns and FITC dye (fluorescein-5-isothiocyanate) [14]. The biomass of fungi was determined, by assuming the weight of $1 \mathrm{~m}$ of mycelium equal to $1.1 \cdot 10^{-6} \mathrm{~g}$. The number of viable fungi was found by the plating method on wort agar with streptomycin. Separation of fungi was realized from this same medium. The identification of microscopic fungi was done based on keys [15-18]. Species names of fungi were specified according to lists in the database "Species fungorum" (www.speciesfungorum.org). For characterization of structure of fungal communities are used indices of spatial and temporal occurrence frequency of species [19] (see the bottom).

The fungus Aspergillus niger was used as a test cul- ture, capable of changing pigmentation of spores, depending on the nutrient medium composition [20]. The fungus was grown on liquid wort with addition of $\mathrm{NaF}$. Concentrations of fluorine ion were, mg/l: 50, 100, 500, 1000,1500 . The control wort did not have $\mathrm{F}^{-}$. Each variant comprised three replications. Incubation was carried out within 7 days at $+27^{\circ} \mathrm{C}$.

\subsection{Chemical Analyses of Soil}

The content of fluorine in organic horizon was found by ionselective method using the $\mathrm{pH} / \mathrm{ION}$ ANALYSER after burning soil at temperature of $950^{\circ} \mathrm{C}$ and fusion of ashes with borax. The total composition of organic horizons was determined after burning soil of the sample $\left(950^{\circ} \mathrm{C}\right)$ and fusion of ashes with soda. Si was found using the weight method, while $\mathrm{P}$ and $\mathrm{Ti}$ were determined by colorimetri, $\mathrm{K}$ and $\mathrm{Na}$ - using a flame photometer, other elements using the AAS-method in accredited laboratoty INEP.

\subsection{Statistics}

Quantitative ecological indices (Shannon, Pielu, Simpson), characterizing the structure of the fungal community, have been calculated by Odum [21]. The obtained data have been processed by means of Excel 2003 statistical programs.

\section{RESULTS AND DISCUSSION}

\subsection{The Content of Macro- and Microelements in Soil}

A considerable part of components contained in air emissions from KAS, gets into the soil surface in the form of solid falls [22]. They cause essential accumulation of mineral substances in the organic horizon of soil, as a result of the ash content in the heavily polluted organic horizon reaches $60 \%$ while the background area does not exceed $10 \%$, and the carbon and nitrogen content decreases 2 times (Table 1). The increase of the ash content in organic horizons took place as a result of an increase in the content of most of the chemical elements. The most evident dependence of the total content on the intensity of pollution is observed concerning $\mathrm{Si}, \mathrm{Al}$ and Ti. The content of heavy metals $\mathrm{Zn}, \mathrm{Cr}, \mathrm{Mn}$ and $\mathrm{Cu}$ also increases. So the quantity of $\mathrm{Cr}$ here exceeds 7 times while $\mathrm{Zn}$ almost 3 times, compared to the content in the

$$
\begin{gathered}
\text { Spatial frequency, } \%=\frac{\text { Number of samples in which the species was found }}{\text { Total number of samples analysed }} \bullet 100 \\
\text { Temporal frequency, } \%=\frac{\text { Number of sampling period in which the species was found }}{\text { Total number of sampling period }} \bullet 100
\end{gathered}
$$


Table 1. Chemical composition of organic horizon $(n=162)$.

\begin{tabular}{|c|c|c|c|c|c|c|c|c|}
\hline \multirow{2}{*}{$\begin{array}{l}\text { Distance, } \\
\mathrm{km}\end{array}$} & $\mathrm{SiO}_{2}$ & $\mathrm{Al}_{2} \mathrm{O}_{3}$ & $\mathrm{Fe}_{2} \mathrm{O}_{3}$ & $\mathrm{TiO}_{2}$ & $\mathrm{CaO}$ & $\mathrm{MgO}$ & $\mathrm{P}_{2} \mathrm{O}_{5}$ & $\mathrm{~K}_{2} \mathrm{O}$ \\
\hline & \multicolumn{8}{|c|}{$\%$ of dry matter } \\
\hline 2 & $28.0 \pm 4.19$ & $17.80 \pm 0.28$ & $3.67 \pm 0.06$ & $0.60 \pm 0.01$ & $0.38 \pm 0.03$ & $0.88 \pm 0.00$ & $0.29 \pm 0.02$ & $0.88 \pm 0.01$ \\
\hline 5 & $11.71 \pm 0.86$ & $6.21 \pm 0.39$ & $1.59 \pm 0.08$ & $0.19 \pm 0.01$ & $0.36 \pm 0.02$ & $0.33 \pm 0.04$ & $0.24 \pm 0.01$ & $0.32 \pm 0.05$ \\
\hline 10 & $8.74 \pm 0.08$ & $4.6 \pm 0.12$ & $2.26 \pm 0.02$ & $0.16 \pm 0.00$ & $0.28 \pm 0.01$ & $0.29 \pm 0.00$ & $0.23 \pm 0.01$ & $0.27 \pm 0.01$ \\
\hline 20 & $4.66 \pm 1.31$ & $1.51 \pm 0.29$ & $0.68 \pm 0.10$ & $0.06 \pm 0.01$ & $0.45 \pm 0.02$ & $0.20 \pm 0.01$ & $0.24 \pm 0.01$ & $0.19 \pm 0.02$ \\
\hline \multirow{2}{*}{ Distance, $\mathrm{km}$} & F & \multicolumn{2}{|c|}{$\mathrm{Al}$} & $\mathrm{Mn}$ & $\mathrm{Zn}$ & $\mathrm{Cr}$ & $\mathrm{Ni}$ & $\mathrm{Cu}$ \\
\hline & \multicolumn{8}{|c|}{$\mathbf{M g} / \mathbf{k g}$} \\
\hline 2 & $2587 \pm 136$ & \multicolumn{2}{|c|}{$256000 \pm 2800$} & $384 \pm 58$ & $201 \pm 7$ & $85 \pm 12$ & $80 \pm 9$ & $104 \pm 9$ \\
\hline 5 & $711 \pm 57$ & \multicolumn{2}{|c|}{$781000 \pm 3900$} & $273 \pm 34$ & $109 \pm 10$ & $35 \pm 4$ & $86 \pm 6$ & $59 \pm 1$ \\
\hline 10 & $360 \pm 26$ & \multicolumn{2}{|c|}{$108000 \pm 1200$} & $207 \pm 25$ & $111 \pm 14$ & $28 \pm 3$ & $128 \pm 1$ & $84 \pm 5$ \\
\hline 20 & $114 \pm 13$ & \multicolumn{2}{|c|}{$9000 \pm 2900$} & $161 \pm 35$ & $73 \pm 3$ & $12 \pm 3$ & $117 \pm 7$ & $53 \pm 9$ \\
\hline
\end{tabular}

organic horizon of the background plot.

If we estimate the content of heavy metals and compare it to the indicators of maximum permissible concentrations (MPCs) it can be noted, that in the most polluted organic horizon the content of $\mathrm{Cu}$ had reached the MPC for $\mathrm{Cu}$, which according to Kloke [23] is 100 $\mathrm{mg} / \mathrm{kg}$ for soil. The contents of $\mathrm{Zn}$ and $\mathrm{Cr}$ are below the MPCs (300 and $100 \mathrm{mg} / \mathrm{kg}$, respectively). The amount of $\mathrm{Ni}$ in all soil samples exceeded 2 and more times the MPC for $\mathrm{Ni}(50 \mathrm{mg} / \mathrm{kg})$, possibly additional Ni comes from the Severonikel plant located $100 \mathrm{~km}$ to the north of the studied area. As a whole we can note that the long-term impact on soils of industrial deposition from the aluminium plant the pollution level with heavy metals has not reached the critical state.

The distribution of total fluoride in organic horizon along the pollution gradient is presented in Figure 1. A clear dependence of the content of fluoride in soil on the distance from the source of emissions can be seen. The most abrupt drop of the content of total fluoride is observed throughout the first $2 \mathrm{~km}$ from the emission source, the farther from the plant the lower is the content of fluoride.

There were identified three zones, differing by the intensity of the pollution of organic horizon of the forest podzol soil with fluoride (Table 2). In the zone of maximum pollution the fluoride content in organic horizon exceeds the MPC of F (200 mg/kg) 25 times. In the zone of strong pollution the total content of fluoride in soil exceeds the MPC almost ten times, and in the zone of moderate pollution - two times. The shares of water-soluble fluorides are on the average $10.3 \%$ of the total content of fluoride in organic horizon.

Near the plant an abrupt decrease of soil acidity $(\mathrm{pH}$

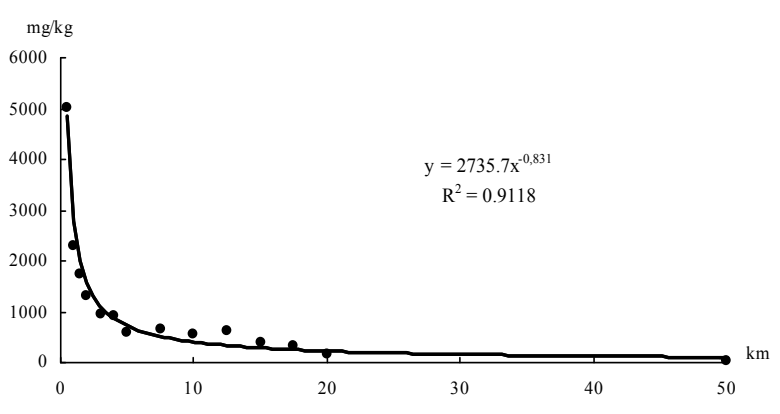

Figure 1. Content of total fluorine in soil $(\mathrm{mg} / \mathrm{kg})$ along the pollution gradient from KAS (mean data, $n=42$ ).

Table 2. Zones of soil pollution (organic horizon) with fluorine.

\begin{tabular}{ccc}
\hline Pollution level & Distance, $\mathrm{km}$ & $\mathrm{F}, \mathrm{mg} / \mathrm{kg}$ \\
\hline Maximum & $0-2$ & $>1200$ \\
Strong & $2-13$ & $1200-400$ \\
Moderate & $13-20$ & $400-200$ \\
Background & $>20$ & $<200$ \\
\hline
\end{tabular}

water suspension from 4.05 to 5.75 ) is observed. This is connected with the neutralization of the bases $\mathrm{Mg}$ and Ca contained in the emissions.

Thus, the influence of emissions from the KAS has affect on not only the fluoride content in soil but has also led to considerable accumulation in the organic horizon of mineral substances, including many macro-and microelements. The influence of solid emissions was so high that it caused a basic change of the ratio of organic and mineral parts of the organic horizon. In the zone of maximum pollution the mineral part became a main com- 
ponent of the upper soil horizon.

\subsection{Number, Biomass, Diversity of Fungi and Structure of Fungal Communities in Soils Polluted with Fluoride}

The emissions from the KAS have in the most considerable way affected the number and diversity of fungi. There have been observed a decrease of the number and biomass of fungi as the degree of soil pollution with emissions of aluminium plant is increasing using both the methods: of plating and the method of fluorescent microscopy.

The quantity of fungi colony-forming units (CFU) in the organic horizon of the plot located $2 \mathrm{~km}$ from the plant is 5 times less than the CFU number in the soil of plots at the distance of 10 and $20 \mathrm{~km}$ from the plant, and 9 times in comparison with the background plot (Figure 2). The length of fungal mycelium was reduced from $5000 \mathrm{~m} / \mathrm{g}$ in the soil of the background to $3000 \mathrm{~m} / \mathrm{g}$ in the most polluted soil plot $(\mathrm{t}=12.4, \mathrm{p}<0.001)$, and the biomass from $5.4 \mathrm{mg} / \mathrm{g}$ to $3.6 \mathrm{mg} / \mathrm{g}$.

There were isolated 44 species of microscopic fungi from the soils of stationary plots. They related to 18 genera, 6 orders, 4 classes and 3 divisions (Table 3). There have been revealed distinctions in taxonomic diversity of soil fungi in the background and polluted soils. In the polluted soil a tendency of reduction of species diversity of fungal communities, a change of their composition and structure compared to the background soil is observed. In the most polluted soil 26 species of microscopic fungi have been identified, 29 species in the strong polluted soil and 35 species in the background soil.

The dominating position in podzols of the Kola Peninsula is occupied by fungi of Penicillium genus [24], which is characteristic also for the podzols polluted with fluoride. In the maximum polluted soil this genus is pre-

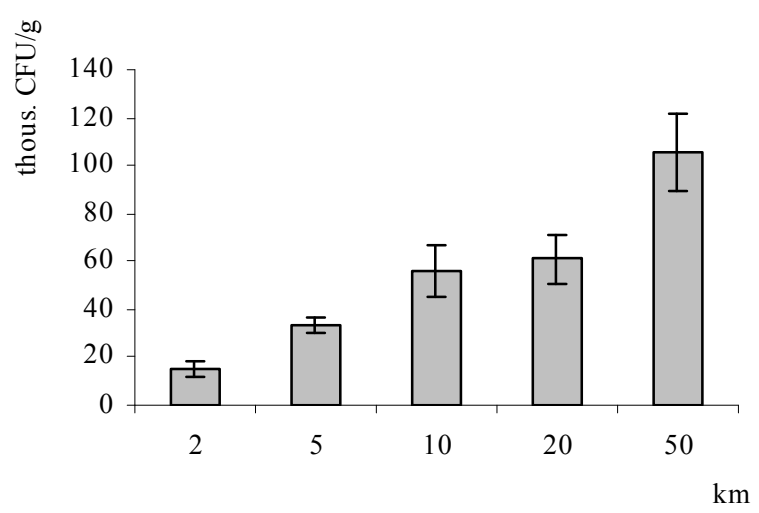

Figure 2. Changes of fungal number (thous. CFU/g) in soil along the pollution gradient from KAS. sented by 10 species, in the strong polluted one by 14 , and in the background by 13 species. The representatives of Mucorales order, sensitive to emissions of the aluminium enterprise, are more widely spread in the background soil.

Under the influence of emissions from the aluminium plant essential changes in the structure of the fungal communities have taken place. Indices of spatial and temporal occurrence frequency of species are calculated. Based on these indices the dominating species in the fungal communities as defined as (spatial and temporal occurrence frequency $>60 \%$ ), frequent (spatial and temporal occurrence frequency $>30 \%$ ), rare (spatial occurrence frequency $<30 \%$, and the temporal one $>30 \%$, and casual species (both indices $<30 \%$ ).

In the polluted soil the following species dominates: Penicillium canescens, $P$. decumbens and $P$. raistrickii, in the background: $P$. implicatum, P. decumbens, Umbelopsis isabellina and Mortierella longicollis. The frequent species in the polluted soil includes: Aspergillus fumigatus, $P$. glabrum, $P$. ochraceum, $P$. spinulosum, $P$. thomii and Trichoderma viride, and in the background: Acremonium rutilum, Aspergillus fumigatus, Aureobasidium pullulans var. pullulans, Cladosporium herbarum, $P$. adametzii, $P$. restrictum, $P$. glabrum and $P$. canescens.

Only in the polluted soil there are revealed rare or quite atypical species for zonal soils: Aspergillus niger var. niger, Paecilomyces variotii, $P$. chermesinum, $P$. variabile, Phoma medicaginis, Thielaviopsis basicola, Torula allii, Myxotrichum cancellatum and Trichocladium asperum. Only in the background soil was found Mortierella alpina, Mucor plumbeus, $M$. racemosus, $P$. lividum, P. citrinum, Sordaria macrospora and Trichoderma polysporum.

Under the influence of industrial emissions from the aluminium plant the part of pathogenic and potentially pathogenic species causing various kinds of mycoses of both endogenous and exogenous character increases in the fungal community. At the background plot, the part of potentially pathogenic fungi is $25 \%$, and at the polluted one $-40 \%$ of the total population of species. This include first of all opportunistic mycoses pathogens from genera Aspergillus (A. fumigatus, A. niger), Cladosporium (C. herbarum) and Paecilomyces (P. variotii) [25,26]. The ones that possessing pathogenic properties are $\mathrm{Al}$ ternaria alternata, Aureobasidium pullulans, P. aurantiogriseum, $P$. glabrum, $P$. simplicissimum, Trichoderma viride and $T$. koningii, these are causing diseases of respiratory and digestive systems.

Quantitative ecological indices confirm the conclusions about the decrease of species diversity and the change of the structure of fungal communities in the soils 
Table 3. Species composition and occurrence frequency of fungi were separated from soil polluted with fluorine.

\begin{tabular}{|c|c|c|c|}
\hline \multirow{2}{*}{ Species } & \multicolumn{3}{|c|}{ Occurrence frequency, $\%$} \\
\hline & $2 \mathrm{~km}$ & $10 \mathrm{~km}$ & $50 \mathrm{~km}$ \\
\hline & Division Zygomycota & & \\
\hline & Class Zygomycetes & & \\
\hline & Order Mucorales & & \\
\hline Gongronella butleri (Lendn.) Peyronel et Dal Vesco & - & $28 / 20$ & $20 / 20$ \\
\hline Mortierella alpina Peyronel & - & - & $25 / 20$ \\
\hline M. longicollis Dixon-Stew. & $37 / 40$ & $65 / 80$ & $62 / 60$ \\
\hline Mucor plumbeus Bonord. & - & - & + \\
\hline M. racemosus Fresen. & - & - & $15 / 20$ \\
\hline Mucor sp. & - & $40 / 40$ & $10 / 40$ \\
\hline Umbelopsis isabellina (Oudem.)W.Gams & - & $27 / 30$ & $70 / 60$ \\
\hline \multirow[t]{4}{*}{ U. ramanniana (A.Mǿller)W.Gams } & $24 / 20$ & - & $32 / 20$ \\
\hline & Division Ascomycota & & \\
\hline & Class Pyrenomycetes & & \\
\hline & Order Sphaeriales & & \\
\hline \multirow[t]{2}{*}{ Sordaria macrospora Auersw. } & - & - & $10 / 20$ \\
\hline & Order Eurotiales & & \\
\hline \multirow{4}{*}{ Myxotrichum cancellatum W.Phillips } & + & - & - \\
\hline & Mitosporic fungi & & \\
\hline & Class Hyphomycetes & & \\
\hline & Order Hyphomycetales & & \\
\hline Acremonium rutilum W.Gams & $21 / 20$ & $38 / 40$ & $31 / 60$ \\
\hline Alternaria alternata (Fr.:Fr.)Keissl. & - & $20 / 40$ & $40 / 40$ \\
\hline Aspergillus fumigatus Fresen. & $31 / 40$ & $30 / 40$ & $46 / 40$ \\
\hline A. niger var. niger Tiegh. & + & - & - \\
\hline $\begin{array}{l}\text { Aureobasidium pullulans var. pullulans (de Bary) } \\
\text { G.Arnaud }\end{array}$ & $25 / 40$ & $29 / 20$ & $50 / 40$ \\
\hline Cladosporium herbarum (Pers.)Link & - & $15 / 20$ & $35 / 40$ \\
\hline Paecilomyces variotii Bainier & + & - & - \\
\hline Penicillium adametzii K.M.Zalessky & - & $32 / 40$ & $45 / 60$ \\
\hline P. aurantiogriseum Dierckx & - & + & + \\
\hline P. canescens Sopp & $79 / 100$ & $22 / 40$ & $38 / 40$ \\
\hline P. citrinum Thom & - & - & + \\
\hline P. chermesinum Biourge & + & - & - \\
\hline P. corylophilum Dierckx & + & + & - \\
\hline P. decumbens Thom & $75 / 80$ & $72 / 100$ & $61 / 100$ \\
\hline P. dierckxii Biourge & - & $18 / 20$ & $6 / 40$ \\
\hline P. implicatum Biourge & - & $60 / 60$ & $71 / 60$ \\
\hline P. glabrum (Wehmer) Westling & $70 / 40$ & $35 / 40$ & $40 / 60$ \\
\hline
\end{tabular}




\begin{tabular}{|c|c|c|c|}
\hline P. lividum Westling & - & - & + \\
\hline P. ochraceum Bainier:Thom & $35 / 40$ & $15 / 20$ & - \\
\hline P. raistrickii G.Sm. & $72 / 60$ & $63 / 80$ & $28 / 80$ \\
\hline P. restrictum J.C.Gilman et E.V. Abbott & - & $40 / 40$ & $38 / 60$ \\
\hline P. simplicissimum (Oudem.)Thom & - & + & - \\
\hline P. spinulosum Thom & $32 / 40$ & $32 / 40$ & $13 / 20$ \\
\hline P. thomii Maire & $43 / 40$ & $42 / 80$ & $7 / 20$ \\
\hline P. variabile Sopp & $25 / 40$ & - & - \\
\hline Thielaviopsis basicola (Berk. et Broome) Ferraris & + & - & - \\
\hline Torula herbarum (Pers.)Link & $18 / 20$ & $15 / 20$ & - \\
\hline T. allii (Harz) Sacc. & + & - & - \\
\hline Trichocladium asperum Harz & + & - & - \\
\hline Trichoderma koningii Oudem. & $30 / 20$ & $20 / 20$ & $12 / 40$ \\
\hline T. polysporum (Link)Rifai & - & - & $24 / 20$ \\
\hline \multirow[t]{2}{*}{ T. viride Pers. } & $50 / 60$ & $13 / 40$ & $17 / 40$ \\
\hline & Order Agonomycetales & & \\
\hline \multirow[t]{3}{*}{ Mycelia sterilia white } & $84 / 100$ & $60 / 100$ & $62 / 100$ \\
\hline & Class Coelomycetes & & \\
\hline & Order Sphaeropsidales & & \\
\hline Phoma eupyrena Sacc. & - & $22 / 20$ & $10 / 40$ \\
\hline P. medicaginis Malbr. et Roum. & $21 / 20$ & - & - \\
\hline
\end{tabular}

polluted with fluoride (Table 4). The Shannon index, characterising the general species diversity, in the background, heavily polluted and strong polluted soil is 3.05 , 2.35 and 2.08 bits/copies, respectively.

Usually the community composition includes some dominating species of high number and many rare species of low number, which was observed in the community of background soil. In the polluted soils the quantity of dominating species decreases. The value of Simpson index reflecting the representativeness of dominant-species decreases when the distance from the plant increases, opposite trend is observed for the Pielu index for uniformity of species diversity the - it increases.

The Sorensen index $(\mathrm{S})$ characterises the similarity (dissimilarity $=100-\mathrm{S}$ ) in species composition of fungal communities at stationary plots depending on the degree of pollution. The similarity in the fungal community between the maximum polluted $(2 \mathrm{~km}$ from the plant) and the background plot is $50 \%$, i.e. $50 \%$ of fungi species isolated from the background soil have not been found in soils with high level of pollution with fluorine containing compounds. Between the strong polluted (10 $\mathrm{km}$ from the plant) and the background plots the similarity in fungal species composition is considerably above $80 \%$.
Using Aspergillus niger as test-culture it was found that fluorine influences the process of spore formation and pigmentation of fungal spores. These fungi can be a good indicator of the fluorine content in soil. As the concentration of $\mathrm{F}^{-}$increases in the nutrient medium from 0 to $500 \mathrm{mg} / \mathrm{l}$ the colouring of Aspergillus niger spores provides the whole range of shades from black to white (Table 5). At concentration of $\mathrm{F}^{-}=500 \mathrm{mg} / \mathrm{l}$ and more the formation of spore stops.

Thus, one of the reasons of a decrease in fungal biomass in the soils that are exposed to emissions from the aluminium plant is the inhibition by fluorine on the spore-formation process. As whole, emissions from the aluminium enterprise have a reducing effect on the development of soil microscopic fungi, causing a decrease

Table 4. Change of quantitative indices are characterized complexes of soil fungi along the pollution gradient $(n=162)$.

\begin{tabular}{cccc}
\hline \multirow{2}{*}{ Index } & \multicolumn{3}{c}{ Distance from KAS } \\
\cline { 2 - 4 } & $2 \mathrm{~km}$ & $10 \mathrm{~km}$ & $50 \mathrm{~km}$ \\
\hline Shannon index & 2.08 & 2.35 & 3.05 \\
Pielu index & 0.72 & 0.82 & 0.95 \\
Simpson index & 0.38 & 0.34 & 0.18 \\
\hline
\end{tabular}


Table 5. The change of spore pigmentation in Aspergillus niger at various concentrations of ions of fluorine in a nutrient medium.

\begin{tabular}{cc}
\hline Content of $\mathrm{F}^{-} \mathrm{mg} / \mathrm{l}$ & Pigmentation of spores \\
\hline 0 & Black \\
50 & Dark grey \\
100 & Light grey \\
300 & White \\
500 & There are no spores \\
\hline
\end{tabular}

in their number, biomass and increase part of pathogenic and potentially pathogenic species in fungal community.

\section{CONCLUSIONS}

There has been carried out zoning of soils, which are under the impact of air emissions from the aluminium plant (the Kandalaksha plant, Russia). There have been identified three zones based on the degree of soil pollution with fluoride: a zone of maximum pollution up to $2.5 \mathrm{~km}$ from the emission source with content of fluoride from $1200 \mathrm{mg} / \mathrm{kg}$ and more, a zone of strong pollution up to $13 \mathrm{~km}$ from the plant with the content of fluoride between $1200-400 \mathrm{mg} / \mathrm{kg}$ and a zone of moderate pollution up to $20 \mathrm{~km}$ from the source with the content of fluoride between $400-200 \mathrm{mg} / \mathrm{kg}$. The solid falls, which are a part of the air emissions, have caused a basic change of the ratio of organic and mineral parts in the composition of organic horizon. The mineral part (ashes) has increased up to $60 \%$ compared to the background value as a result of accumulation first of all such elements as $\mathrm{Si}, \mathrm{Al}$ and $\mathrm{Ti}$.

Emissions from the aluminium plant have reduced the number and the diversity of fungi and have caused an increase of fungal communities in the part of potential pathogenic fungi. Only in the polluted soil rare or just atypical species for zonal soils are selected: Aspergillus niger var. niger, Paecilomyces variotii, P. chermesinum, P. variabile, Phoma medicaginis, Thielaviopsis basicola, Torula allii, Myxotrichum cancellatum, and Trichocladium asperum. Among these there are activators of opportunistic mycoses. Aspergillus niger is a good indicator of soil pollution with fluorine, changing pigmentation of its spores depending on the quantity of fluorine in the medium.

The industrial deposition from the aluminium plant (the Kandalaksha plant) influences to a lesser degree on soil and vegetation cover than emissions from the copper-nickel enterprise ("Severonikel" and "Pechenganikel"). Only an appreciable damage of tree layer at a distance of $5 \mathrm{~km}$ from the source is observed for the alu- minium plant, compared to the copper-nickel smelter this distance is up to $40 \mathrm{~km}$ in the wind rose.

\section{ACKNOWLEDGEMENTS}

This study was supported by a grant of the Presidium of Russian Academy of Sciences «Biodiversity». We also thank E. Lebedeva for their help in identification of fungi.

\section{REFERENCES}

[1] Evdokimova, G.A. (1982) Microbiological activity of the soils polluted by heavy metals. Soviet Soil Science, 3, 31-38.

[2] Nikonov, V.V. and Lukina, N.V. (1990) Technogenic transformation of forest of north-eastern Fennoscandia with the structure and reserve of organic substance as an example. In: Kinnunen, K. and Varmola, M., Eds., Effects of Air Pollution and Acidification in Combination with Climatic Factors on Forests, Soils and Waters in the Northern Fennoscandia, Nord, 178-194.

[3] Kozlov, M., Haukioja, E. and Yarmishko, V. (1993) Aerial pollution in the Kola Peninsula, Kola Science Centre, Apatity.

[4] Evdokimova, G.A. (1999) Dynamics of the industrial transformation of terrestrial ecosystems in the kola subarctic. In: Peakall, D., Walker, C. and Migula, P., Eds., Biomarkers: A Pragmatic Basis for Remediation of Severe Pollution in Eastern Europe, Kluwer Academic Publishes, 1-14.

[5] Evdokimova, G.A. (2000) The impact of heavy metals on the microbial diversity of podzolic soils in the kola peninsula. In: Innes, J. and Oleksyn, J., Eds., IUFRO № 1. Research series. Forest Dynamics in Heavily Polluted Regions. Task Force on Environmental Change, CABI Publishing, 67-76.

[6] Evdokimova, G.A., Mozgova, N.P. and Shtina, E.A. (1997) Soil pollution by fluorine and evaluation of the soil microflora status in the area of influence of aluminium plant. Eurasian Soil Science, 30(7), 796-803.

[7] Evdokimova, G.A. (2001) Fluorine in the soils and vegetation of the white sea basin and bioindication of pollution. Chemosphere, 42(1), 35-43.

[8] Evdokimova, G.A., Zenkova, I.V., Mozgova, N.P. and Pereverzev, V.N. (2005) Soil and soil biota under conditions of the fluorine contamination. Kola Science Centre, Apatity.

[9] Chaschin, V. (2007) The occurrence of fluorosis among pot room workers. 3th International Conference on Environmental, Health and Safety Aspects Related to Production of Aluminium, Loen, 63.

[10] Kongerud, O. (2007) Hydrogen fluoride and health effects. 3th International Conference on Environmental, Health and Safety Aspects Related to Production of Aluminium, Loen, 44.

[11] Krewskii, D., Yokel, R., Nieboer, D., Borchelt, D., Cohen, J., Harry, J., Kacew, S., Lindsay, J., Mahfouz, A. and Rondeau, V. (2007) Human health risk assessment for aluminium, aluminium oxide and aluminium hydroxide. Journal of Toxicology and Environmental Health, 
10(Suppl 1), 1-269.

[12] Nieboer, E. (2007) Human health risk assesment for aluminium, aluminium oxide, and aluminium hydroxide scientific outcomes. 3th International Conference on Environmental, Health and Safety Aspects Related to Production of Aluminium, Loen, 55.

[13] Taiwo, B. (2007) The incidence of asthma among aluminum production workers. 3th International Conference on Environmental, Health and Safety Aspects Related to Production of Aluminium, Loen, 41.

[14] Olsen, R. and Hovland, J. (1985) Fungal flora and activity in Norway spruce needle litter. Report. Department of Microbiology, Agricultural University of Norway, 25-41.

[15] Raper, K. and Thom, C. (1965) A Manual of the Penicillia, Baltimore.

[16] Rifai, A. (1969) A revision of the genus Trichoderma. Mycological Papers. 116, 1-56.

[17] Ellis, M. (1971) Dematiaceus hyphomycetes. Commonwealth Mycological Institute, Kew.

[18] Domsh, K., Gams, W. and Anderson, T. (1993) Compendium of soil fungi. Academic Press, London.

[19] Mirchink, T., Ozerskaya, S. and Marfenina, O. (1982) The ways of revealing of complexes of microscopic fungi typical for certain conditions based on the characteristic of their structure. Biological Sciences, 11, 61-66.
[20] Korneykova, M. (2008) Aspergillus niger var. niger as bioindicator under the pollution of environment by fluorine and copper. In: Evdokimova, G.A. and Vandish, O.I., Eds., Ecological problems of northern regions and ways of their solution. Kola Science Centre, Apatity, 110-113.

[21] Odum, J. (1975) Basis of ecology. Mir, Moscow.

[22] Evdokimova, G.A. and Pereverzev, V.N. (2003) The effect of emissions from an aluminium smelter on the chemical composition of litter and crowberry (Empetrum hermaphroditum Hager.) plants in pine forests of the Kola Peninsula. Eurasian Soil Science, 36(9), 1018-1022.

[23] Kloke, A. (1983) Tolerable amount of heavy metals in soil and their accumulation in plants. In: Kloke, A., Ed., Environmental Effects of Organic and Inorganic Contaminants in Sewage Sludge, 171-175.

[24] Evdokimova, G.A. and Mozgova, N.P. (2001) Microorganisms of tundra and forest podzols of the Kola North. Kola Science Centre, Apatity.

[25] De Hoog, G., Guarro, J., Gene, J. and Figueras, M. (2000) Atlas of clinical fungi. CBS, Utrecht, Reus, Spain.

[26] Satton, D., Fotergill, A. and Rhinaldi, M. (2001) Key pathogenic and conditionally pathogenic fungi. Mir, Moskow. 